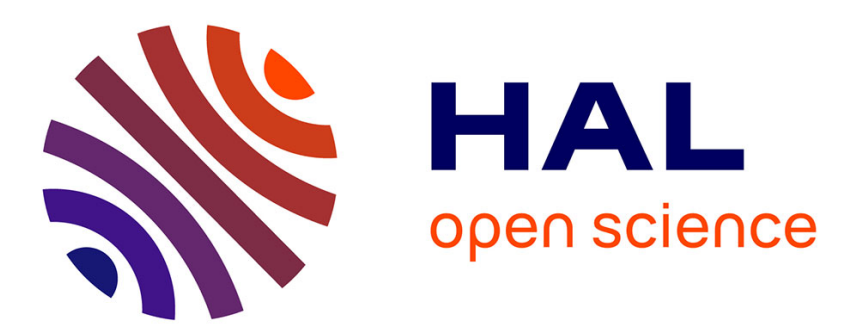

\title{
A Theoretical Multiscale Approach to Study the Initial Steps Involved in the Chemical Reactivity of Soot Precursors
}

Michel Keller, Theodorus de Bruin, Mickaël Matrat, André Nicolle, Laurent Catoire

\section{To cite this version:}

Michel Keller, Theodorus de Bruin, Mickaël Matrat, André Nicolle, Laurent Catoire. A Theoretical Multiscale Approach to Study the Initial Steps Involved in the Chemical Reactivity of Soot Precursors. Energy \& Fuels, 2019, 33 (10), pp.10255-10266. 10.1021/acs.energyfuels.9b02284 . hal-02345853

\section{HAL Id: hal-02345853 \\ https://hal-ifp.archives-ouvertes.fr/hal-02345853}

Submitted on 4 Nov 2019

HAL is a multi-disciplinary open access archive for the deposit and dissemination of scientific research documents, whether they are published or not. The documents may come from teaching and research institutions in France or abroad, or from public or private research centers.
L'archive ouverte pluridisciplinaire HAL, est destinée au dépôt et à la diffusion de documents scientifiques de niveau recherche, publiés ou non, émanant des établissements d'enseignement et de recherche français ou étrangers, des laboratoires publics ou privés. 


\title{
A Theoretical Multiscale Approach to Study the Initial Steps Involved in the Chemical Reactivity of Soot Precursors
}

\author{
Michel Keller, ${ }^{1}$ Theodorus de Bruin, ${ }^{* 1}$ Mickaël Matrat, ${ }^{1}$ André Nicolle, ${ }^{1}$ Laurent Catoire ${ }^{2}$ \\ ${ }^{1}$ IFP Energies nouvelles, $1 \& 4$ avenue de Bois-Préau, 92852 Rueil-Malmaison, France \\ ${ }^{2}$ ENSTA Paristech, 828 Boulevard des Maréchaux, 91120 Palaiseau, France
}

In the present study bond formation reactions between soot precursors and their role in the soot inception process is investigated. The soot precursors were generated in macroscopic detailed gas-phase kinetic calculations and according to certain criteria introduced in simulation boxes to model bond formation between soot precursor molecules with reactive force field molecular dynamics modeling. The impacts of temperature, fuel mixture and equivalence ratio have been investigated on the rate and structure of the newly formed molecules. The resulting structures compare well to previously reported experimental results. Furthermore, the bond formation rate between PAH is found to be linearly correlated with the temperature at which the PAH precursors are generated, while fuel and equivalence ratio do not have a direct impact on the reaction rate. The generated growth structures are lumped in: 1) directly linked, 2) aliphatically linked and 3) pericondensed polycyclic hydrocarbons. It is found that the amount of aliphatically linked PAH increases with the amount of aliphatic content of fuel mixture. Finally, a reaction scheme is presented displaying the most representative reaction pathways to form growth structures in each lumping class and their eventual interconversion. The present work - that applies a combined approach of macroscopic gas-phase kinetic calculations and atomistic reactive force field simulations - offers a good alternative to obtain structural differences of nascent soot for a broad range of thermodynamic conditions and detailed reaction mechanisms for soot inception process.

\section{Introduction}

Soot particles are carbonaceous products formed due to incomplete combustion of the feedstock. They originate from several sources, such as furnaces, forest fires, turbines or internal combustion engines among others. Soot particles have been shown to have a hazardous impact on human health. Inhaled nanoparticles are deposed in the respiratory tract and due to diffusion, they can readily penetrate through the whole body. ${ }^{1}$ Especially the smaller particles have been shown to be more harmful. ${ }^{2}$ Another concern is the influence of soot particles on global climate change. Indeed, soot has been ranked as the second main source for radiative forcing. ${ }^{3}$ Soot particles do not only contribute to global warming due to solar radiation absorption, but their deposition on ice and snow and the mixing in oceans and clouds also have significant effects on radiative balance and weather patterns according to their nanostructure. ${ }^{4,5}$

Soot basic structural units (BSU) consist of a stack of several parallel polyaromatic hydrocarbons (PAH) exhibiting some amount of curvature. The length of the polyaromatic layers within a BSU may differ and varies between BSU. ${ }^{6}$ The quantity of soot generated and the nanostructure of the particles largely depend on their formation conditions. High-resolution transmission electron microscopy (HRTEM) studies by Vander Wal et al. showed that the initial fuel composition, e.g., the aromatic and aliphatic fuel content in the fuel mixture, as well as the temperature have a significant effect on the nanostructure of the soot particles. ${ }^{7}$ Furthermore, under engine conditions not only the fuel and temperature, but also parameters like injection timing, turbulence intensity, exhaust gas recirculation level and the pressure impact the soot structures. $^{8-11}$
It is known that the soot nanostructure greatly influences the reactivity of the soot e.g. oxidation rates. ${ }^{12}$ Soot that incorporates curved graphitic planes has a higher reactivity towards oxidation due to the molecular strain. Additionally, as a result of a better accessibility of $\mathrm{C}$ atoms on the edge sites, an amorphous structure shows higher reactivity. ${ }^{13}$ Moreover, it is known that the chemical composition of the particles, as well as the particle size, does plays a role on health, ${ }^{14}$ although the precise relationship is not well understood. ${ }^{15}$

Accounting for these phenomena is challenging, as the step from the gas-phase towards the particle phase during combustion, the so-called soot inception, is poorly understood. The most widely accepted mechanism for modeling soot particle inception is the irreversible dimerization of two PAH due to $\pi-\pi$ interactions, with the smallest dimerizing PAH being pyrene, due to its thermal stability. ${ }^{16-19}$ Experiments have shown that the size distribution of soot particles in flames exhibits a bimodal behavior, ${ }^{20}$ which may be well reproduced by assuming physical dimerization as the soot inception step. $^{21,22}$ Furthermore, experimental evidence of excimers of aromatic aggregates in flames suggests that physical dimerization plays a role. ${ }^{23}$

While $\pi-\pi$ interactions of pyrene may be strong enough to plausibly describe the formation of dimers under flame conditions ${ }^{19,24}$ there have been concerns regarding the dimerization mechanism of pyrene..$^{22,25-27}$ From dimerization equilibrium constants $^{28,29}$ it appears that pyrene dimerization due to Van der Waals forces is unlikely to play a role in nucleation at combustion temperatures, and an investigation of the potential energy surface (PES) by Violi et al. supports this finding. ${ }^{27}$

Nonetheless, species larger than pyrene like ovalene and hexacoronene may be involved in the nucleation step by dimeriza- 
tion due to Van der Waals forces as the polarizability increases due to the larger aromatic plane. ${ }^{26,27}$ The concentration of these species in the gas-phase during combustion is low, ${ }^{22}$ however, and soot inception was shown to occur before the peak concentration of these species. ${ }^{30}$ Additionally, Violi et al. showed that smaller PAH substituted with aliphatic chains are more likely to form dimers. ${ }^{27,31}$

Since small PAH have too weak Van der Waals interactions to account for the irreversible dimerization, Eaves et al. introduced reversibility to the physical dimerization term in a nucleation study. ${ }^{32,33}$ In order to reproduce experimental findings a chemical bond formation term, describing chemical bonding of PAHs and hence soot inception, was introduced to reduce the reversibility and thereby accounting for the soot inception. The formation of chemical bonds is also assumed in other models ${ }^{34-39}$ to account for the high temperature soot inception and recent experimental studies support these findings. ${ }^{40,41}$ Despite all these previous studies, several issues remain to be worked out and bond formation between soot precursors is not well understood.

Nevertheless, in order to derive expressions for these chemical bond formations theoretical molecular modeling studies need to be performed. Ab initio methods are to date computationally too expensive to get accurate kinetics of the chemical bond formation between larger PAH due to the large number of electrons involved. As a result these rates are usually extrapolated from calculations on smaller aromatics. ${ }^{42}$ Another molecular modeling approach to study the chemical growth on large PAH is based on kinetic Monte-Carlo calculations where chemical growth of a seed molecule is considered and was developed by Violi et al. ${ }^{43,44}$ In this approach it is possible to differentiate nanostructures of soot particles based on different fuels, suggesting that aromatic fuels tend to produce more bent aromatic structures than aliphatic fuels. ${ }^{38,45,46}$ Another recent approach used for modeling soot inception and combustion processes is based on reactive force field molecular dynamics (ReaxFF). ${ }^{47}$ This molecular modeling approach uses a force field that calculates bond orders between atoms, based on the interatomic distance and atomic charges, hence allowing for bond breaking and formation. The force field parameterization uses quantum mechanical calculations, which leads to accuracies close to $a b$ initio methods, while retaining computational efficiency close to classical force field calculations. Using this methodology, soot formation has been investigated in several studies. Zhang et al. modeled carbon black formation from acetylene and methane pyrolysis under high pressures using ReaxFF. ${ }^{48,49}$ They found that during the pyrolysis small radicals first polymerize into longer chains, that in turn form ring structures and finally coalesce into one large particle. Han et al. modeled the combustion of a 24component fuel to investigate the soot inception process using ReaxFF. ${ }^{50}$ They interestingly showed that soot formation followed three distinct stages: the formation of the first ring, coalescence of smaller molecules into bigger structures and finally a graphitization stage. Furthermore, Mao et al. modeled physical and chemical soot nucleation of intermediatesized PAH using ReaxFF by modeling homo-molecular dimerization at different temperatures, producing dimerization kinetics of physically and chemically bound PAH in dependence of the temperature. ${ }^{51,52}$ They showed that in dependence of the size of the PAH the temperature at which physical dimerization occurs differs, while homo-molecular bond formation only occurred at elevated temperatures independent of the
PAH size. ${ }^{51}$ In a further study they investigated the kinetics and lifetime of homobinary collision of PAH molecules and radicals. ${ }^{53}$ They revealed an influence of molecular size, the number of radical sites in the molecule and the temperature on the dynamics of the dimerization process. Additionally they showed that metal atoms could assist bond formation between $\mathrm{PAH}^{54}$ Yuan et al. showed that an estimated mixture of small PAH and smaller radicals, which are found in abundance during combustion, produces large molecules using ReaxFF at experimental flame temperatures. ${ }^{55}$ They showed that with different mixtures of PAH and radicals the polymerization process between PAH follows different pathways. They notably found that at low temperatures the soot formation mechanism is governed by physical forces and direct carbon addition, while at higher temperatures radical reactions play a more dominant role. ${ }^{55}$

Wang categorized the soot nucleation process into three pathways: ${ }^{56}$ the first being the stepwise growth of soot from addition of smaller molecules, the second being dimerization of soot precursor molecules due to $\pi$ - $\pi$-interactions and the third being the reactive bond formation (also called coalescence) between soot precursor molecules. In the present study the third pathway is investigated and chemical bond formation between soot precursor molecules is modeled in order to understand structural differences of nascent soot particles. For this a multiscale coupled approach of reactor kinetics modeling and molecular dynamics is employed, in order to map out a wide range of combustion conditions. To achieve this goal a gas-phase reactive system composition is obtained from a homogeneous reactor simulation under different thermodynamic conditions, including initial fuel composition, equivalence ratio and temperature. The gas-phase mixture is then post processed, as detailed in the methodology section. This is done in order to make it suitable to run atomistic reactive force field calculations with the extracted gas phase. Essentially, smaller molecules are filtered out, while the PAH that potentially could contribute to soot or BSU formation through bond formation, the so-called soot precursors, are conserved and their chemical growth is modeled using ReaxFF. It is expected that due to the compositional differences in the soot precursor pool, the growth and as a result the nanostructure of the soot will differ. Here, we propose a way to rationalize the expected correlation between the initial conditions and the resulting soot nanostructure. This would allow for a better understanding of the differences in molecular structure of nascent soot based on the combustion conditions and could therefore help to explain the differences in oxidation behavior.

\section{Methodology}

Phenomenological kinetics modeling. The fuel combustion was simulated in a closed homogeneous reactor as implemented in the Chemkin software ${ }^{57}$ under constant pressure and constant temperature. Simulations were run for 0.2 seconds at a pressure of $10 \mathrm{~atm}$ to approach internal combustion engines thermodynamic conditions. The fuel mixture was varied from $100 \mathrm{~mol} \% \mathrm{n}$-decane to $100 \mathrm{~mol} \%$ toluene, in a stepwise substitution of $20 \mathrm{~mol} \%$ in order to test the influence of aromatic and aliphatic content in the fuel on the structure of the generated soot. The detailed chemical kinetic mechanism of Raj et al. $^{58}$ was used as it allows simulating reactivity of gasoline and diesel surrogates and includes $\mathrm{PAH}$ growth up to coronene. 


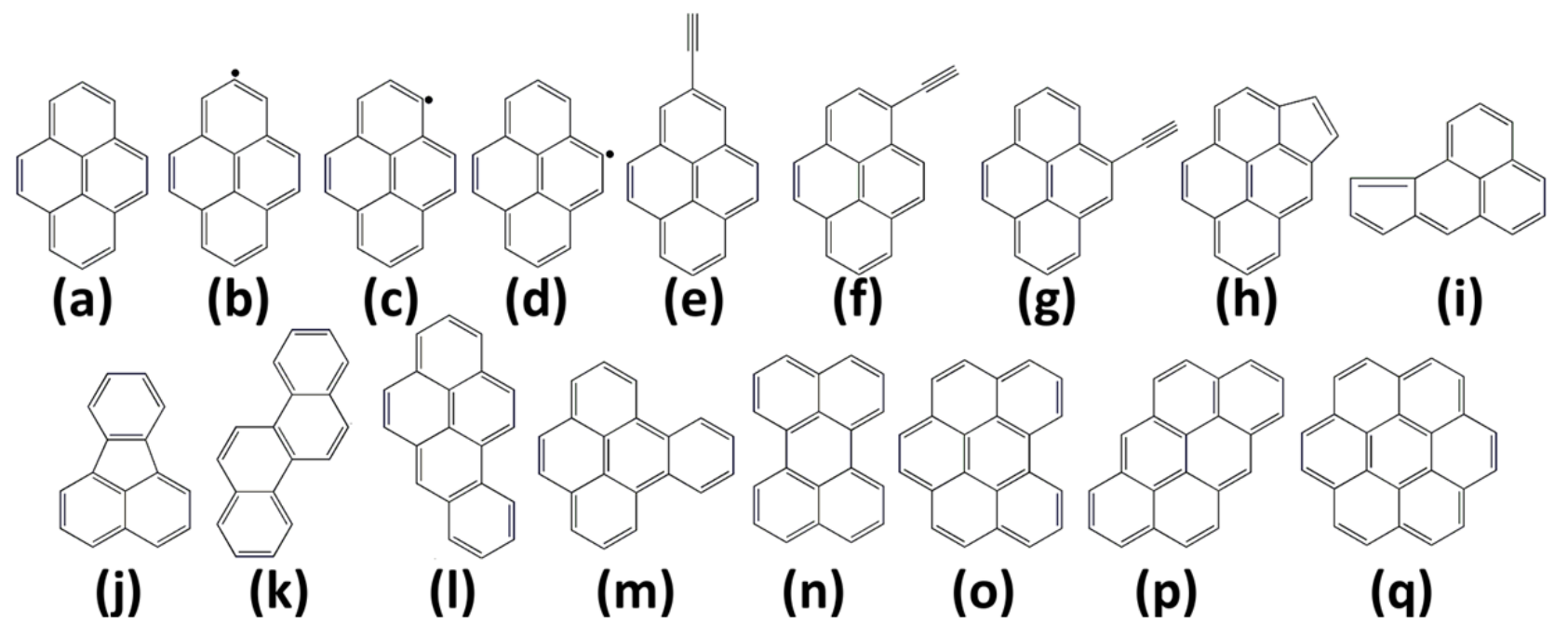

Figure 1. PAH considered for the generation of the precursor pool for the ReaxFF simulations. (a) pyrene, (b) 1-pyrenyl radical, (c) 2pyrenyl radical (d) 3-pyrenyl radical, (e) 1-(1-pyrenyl)acetylene, (f) 1-(2-pyrenyl)acetylene, (g) 1-(4-pyrenyl)acetylene, (h) cyclopenta[cd]pyrene, (i) cyclopenta[1,2]phenalen, (j) fluoranthene, (k) chrysene, (l) benzo[a]pyrene, (m) benzo[e]pyrene, (n) perylene, (o) benzo[ghi]perylene, (p) anthanthrene, (q) coronene.

The mechanism proposed by Raj et al. ${ }^{58}$ was validated against fuel-rich premixed sooting flames. Especially PAH concentration profiles in this mechanism could be improved in regard to earlier mechanisms. ${ }^{58,59}$ There are few other publiclyavailable mechanisms to predict large $\mathrm{PAH}$ formation covering aromatic-containing surrogate mixtures of commercial liquid fuels, ${ }^{60-62}$ and several newly developed mechanisms have Raj's mechanism as a basis to predict the formation of larger PAH. ${ }^{59,63-65}$ As a result, the PAH formation from Raj's mechanism and updated versions of the mechanism has been validated in several experimental studies. ${ }^{58,59,65,66}$ Testing updated versions for the generation of the soot precursor pools gave similar results as using Raj's mechanism, hence reassuring the validity of the approach.

The temperature ranges from $1400 \mathrm{~K}$ to $2000 \mathrm{~K}$, in steps of 200 degrees, and is kept constant in the closed homogeneous reactor over the simulation time. This is done in order to decouple the thermal and chemical impact of fuel composition by performing the precursor pool generation at fixed temperatures and pressures, allowing a careful comparison of the impact of fuel composition on precursors pool. The tested equivalence ratio $\Phi$ (the mixtures description is given in the Supporting Material) ranges from 2.5 to 5 with steps of 0.5 .

Both the temperature range and equivalence ratios were chosen to cover combustion conditions that are known to produce soot. $^{67,68}$ The Chemkin output is post-processed to extract a precursor pool for the initial configuration of the ReaxFF simulations to describe the soot growth reactions on soot BSUs. For example, small non-reactive molecules like molecular nitrogen, were filtered out, since they increase the number of atoms to be taken into account, thereby increasing the computation time. The objective is then to select a representative onset of soot formation from the chemical kinetic calculations performed. Experimental results show that pyrene mole fraction in the gas phase is closely related to the soot onset. ${ }^{30}$ For this reason we identified the pyrene mole fraction as an indicator for the soot inception. Furthermore, rate-of-production analyses based on Raj's mechanism (see Supplementary Materials for a detailed discussion) tend to indicate that the PAH production larger than pyrene is mainly the result of pyrene consumption. ${ }^{58}$ Hence, under fuel-rich conditions and temperatures beneath $2000 \mathrm{~K}$, a peak in the pyrene mole fraction indicates a conversion of pyrene into larger species and therefore can be assumed to indicate the onset of soot inception. To get a consistent description of the gas-phase composition prior to soot inception, we selected the point at which half of the maximum of the mole fraction of pyrene is reached within the $0.2 \mathrm{~s}$ simulation time.

Still, the pyrene mole fraction is typically present at the ppm scale; a corresponding molecular simulation box containing only one pyrene molecule, would comprise almost one million other molecules. This yields an ensemble with a total number of atoms (N) close to tens of millions of atoms, thereby assuming that each molecule possesses an average 10 atoms. Such systems become too large for daily routine molecular dynamics simulations. Therefore, selection criteria were applied. The first criterion ensures that half of the maximum mole fraction of pyrene exceeds the ppm-level in order to assure that a sufficient number of soot precursors are present. The second criterion is to select only aromatic molecules with four or more rings and to discard the mole fractions of smaller molecules in the MD simulations. This latter criterion ensures the presence of pyrene and PAH of the size of pyrene, which has been shown crucial in soot formation experiments. $^{19,20,23,24,30,69}$ On the other hand, if the smaller-sized aliphatics and aromatics would be included, they would dominate the gaz phase composition. However, since their composition hardly changes under the considered thermochemical conditions, the overall gaz-phase composition used in the ReaxFF simulations would barely change. 


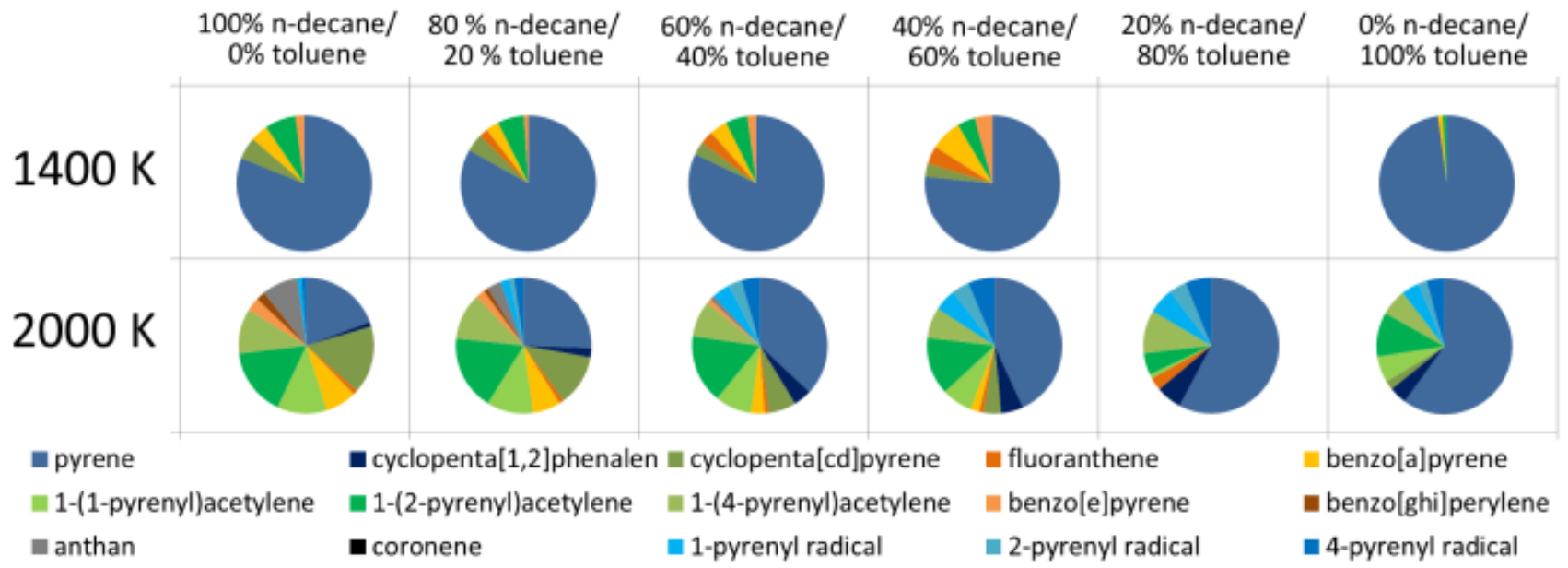

Figure 2. Extracted soot precursor compositions for all fuel mixtures at equivalence ratio 3.5 and temperatures of $1400 \mathrm{~K}$ and 2000 $\mathrm{K}$. Note that the pie-chart at $1400 \mathrm{~K}$ and $20 \%$ n-decane $/ 80 \%$ toluene is not depicted, since the selection criteria for pyrene are not get reached (see section 2.1).

The considered molecules are shown in figure 1. The presented pool of considered molecules may not necessarily represent the actual gas phase under experimental conditions, since it lacks molecules smaller than pyrene and also other PAH potentially present in the gas phase. The Raj mechanism was chosen in the Chemkin calculations, as it gives a reasonable distribution of PAH. The selected PAH include several features which contribution to the bond formation mechanism between PAH is investigated in this study, like aliphatic side chains, five membered rings, different aromatic sites and radicals. $^{70-74}$

Based on the above-mentioned selection criteria we generated a ReaxFF-input gas mixture. The total mole fraction of the selected PAH varies between 10 and $900 \mathrm{ppm}$ of the total mole fraction of the initial gas phase when changing the temperature, equivalence ratio and fuel compositions. To normalize the compositions, the individual PAH mole fractions were summarized and the percentage distributions of the PAH mole fractions in the sum were used to account for the number of molecules in the ReaxFF simulation, in order to obtain molecular dynamics boxes with a maximum of 100 molecules for each of the different compositions. The extracted compositions from the Chemkin calculations are given in figures S1S4 and tables S2-S7 in the Supplementary Material.

Reactive force field molecular dynamics. The ReaxFF calculations were performed using the SCM ADF modeling suite $^{75}$ within the NVT ensemble at $2500 \mathrm{~K}$ with a NoséHoover thermostat, a damping constant of $10 \mathrm{fs}$ and a time step of 0.1 fs and employing the force field published by Chenoweth et al. ${ }^{76}$ This fixed, relatively high temperature was chosen in order to accelerate the occurrence of chemical reactions, thereby reducing the computation times, without significantly alternating the reaction paths. This artificial speedup is quite common practice $\mathrm{f7}^{72}$ and was also recently used by Mao et al. ${ }^{51}$ on similar molecular systems. Simulations at lower temperatures (e.g., $2000 \mathrm{~K}$ ) executed with longer simulations times indeed showed similar results supporting this assumption.

The density of the simulation boxes was chosen to correspond to the pressure of $10 \mathrm{~atm}$ used in the Chemkin calculations, which correspond to densities representative of real engine conditions. ${ }^{83}$ Hence, the densities of the different soot precursor mixtures vary from 0.013 to $0.015 \mathrm{~g} / \mathrm{cm}^{3}$. The statistics of the MD simulations were improved by using three different initial starting geometries for each condition. The different initial geometries, i.e. different initial atomic coordinates and initial velocities, are used in order to limit a bias towards a certain reaction due to an immediate vicinity of two molecules at the beginning of the calculation.

All systems were thermochemically equilibrated for $100 \mathrm{ps}$ at $2500 \mathrm{~K}$ with the reactivity turned off by preventing bond orders to change between atoms. After equilibration of the temperature, the bond order algorithm of ReaxFF was turned on, to allow for bond breaking and formation. The simulations were run for $2 \mathrm{~ns}$. At the end of each calculation, every structure which molecular weight exceeded the initial maximal mole mass of the starting composition, was detected as a growth-structure. Thereafter, the structural features and reaction pathway of each growth structure detected has been investigated.

\section{Results \& Discussion}

Impact of the combustion conditions on the soot precursor pool. Scanning the above mentioned different fuel mixtures, equivalence ratios and temperatures, 144 different conditions were tested from which it was possible to generate 128 distinct PAH mixtures, following the selection criteria to generate the input compositions for the MD calculations. Figure 2 shows the extracted compositions obtained from the Chemkin calculations for a number of cases. All compositions over the range of conditions studied is shown and discussed in the supplementary material. The impact of the equivalence ratio on the extracted precursor mixture composition was found to remain modest over the investigated range of 2.5 to 5.0, although it has a significantly larger impact at $\Phi<2.5 .^{69,84}$ However, since soot formation is the target of this study, we only tested fuel-rich mixtures $(\Phi>2.5)$, as soot is most likely to form under these conditions. Hence, the compositions are shown for only one (i.e. the median) equivalence ratio.

Figure 2 shows the principal compositions as extracted from the Chemkin calculations for two illustrative cases at the minimum $(1400 \mathrm{~K})$ and maximum $(2000 \mathrm{~K})$ temperatures. The 
compositions for all other studied cases can be found in the supplementary materials. From Figure 2 it follows that at both temperatures the pyrene content steadily increases upon increasing the aromatic content in the fuel. At $1400 \mathrm{~K}$ the toluene-rich fuel compounds almost exclusively yield pyrene, while at $2000 \mathrm{~K}$ especially at aliphatic-rich fuels, the obtained mixtures contain acetylated-pyrenes.
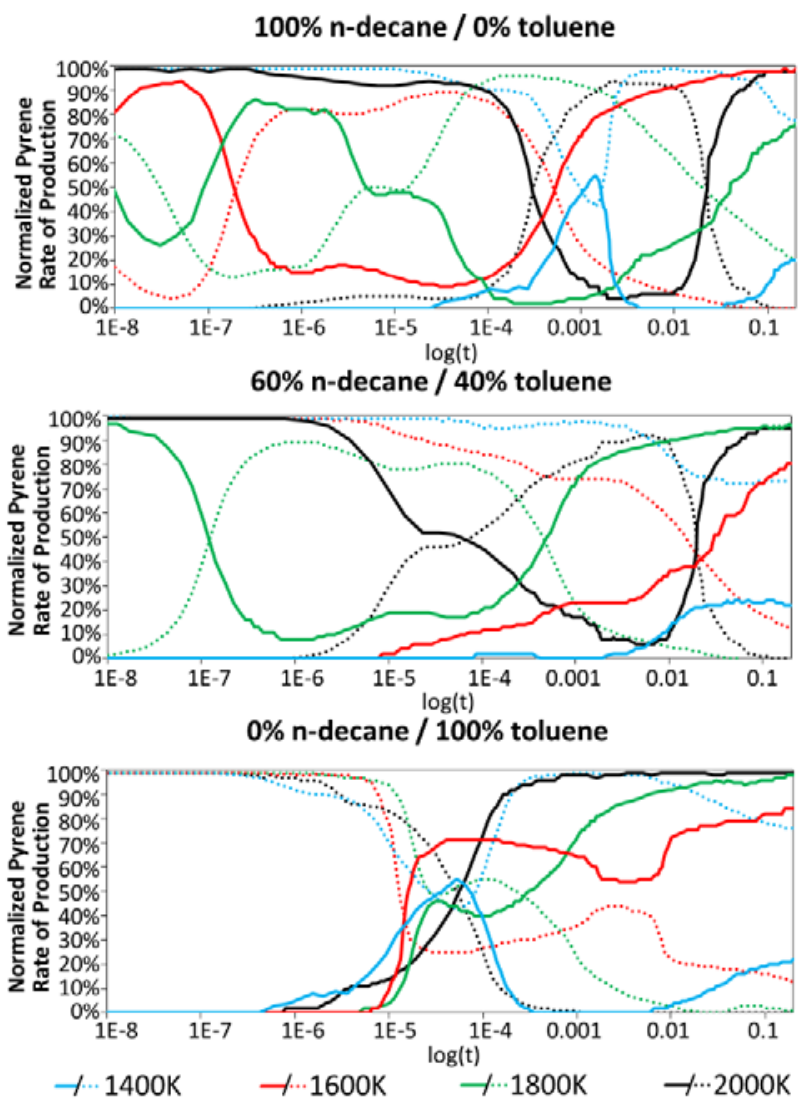

Figure 3. Rate of production of pyrene by the addition of smaller aliphatic species to aromatic molecules (solid line) and the reaction of equally-sized aromatic molecules (dashed line) as a function of time (s). The contribution of these two distinct pathways for the pyrene production are shown for three distinct fuel mixtures and all temperatures at eq. ratio 3.5.

Rate-of-production analyses of pyrene in Raj's mechanism show that one can distinguish the production of pyrene into two separate pathways: 1) formation of pyrene by the addition reaction of two, roughly equally-sized, aromatic species and 2) the stepwise addition of smaller (aliphatic) fragments to an aromatic molecule. The influence of temperature and fuel mixture on the percentage contribution of these two pathways towards the production of pyrene is depicted in Figure 3. A detailed discussion of the rate-of-production- analysis of the formation of pyrene by the seven most contributing reactions is given in the supplementary material.

Figure 3 clearly shows that at $1400 \mathrm{~K}$ almost all pyrene production results from the stepwise addition reaction of equally sized aromatic species with one another (dashed line). Only for short periods in the time simulated, the pathway by addition of aliphatic species gains significance. A change of fuel influences the contribution of the pathways only in a minor fashion at $1400 \mathrm{~K}$ and the pathway of pyrene formation by reaction of two aromatic species remains dominant. The pathway of pyrene formation by addition of smaller aliphatics to aromatics (solid line) gains significance at temperatures above $1400 \mathrm{~K}$, which results from a larger mole fraction of small aliphatic species and radicals in the gas phase due to a faster fragmentation of the fuel molecules at increased temperatures In Raj's mechanism, the growth of species larger than pyrene is described by the stepwise addition of acetylene to PAH radicals. This process is known as the hydrogen abstraction - $\mathrm{C} 2 \mathrm{H} 2$ - addition (HACA) mechanism and widely accepted for soot surface growth. ${ }^{16,85-88}$ The only species included in the extracted precursor compositions that does not follow this growth mechanism is fluoranthene (Figure $1 \mathrm{j}$ ).

The reactions involving small molecules (solid lines in Figure 3) gain in significance with increasing temperatures, owning to an increased fuel consumption and faster fragmentation of the fuel molecules with increasing temperatures. As a result, the amount of small radicals found in the gas phase increases and the pathways leading to pyrene and larger PAH by addition of smaller radicals to aromatics is favored. Therefore, at elevated temperatures also PAH other than pyrene are more present. As the growth pathways of these PAH in Raj's mechanism imply the HACA mechanism, the increased acetylene mole fraction - resulting from the faster fuel fragmentation at increased temperatures - is the reason for the higher diversity of the soot precursor pool compositions with increasing temperature.

The influence of the fuel mixture on the diversity of the extracted precursor pools follows the same trends. In Raj's mechanism, the growth of pyrene and larger aromatics from ndecane is described by the fragmentation of n-decane into smaller radicals followed by the recombination to form aromatic species. For toluene-rich fuels, pyrene growth is significantly different, since toluene and its fragmentation products already consist of an aromatic ring. As a result, the formation of pyrene from toluene follows a more direct path in Raj's mechanism and a significant amount of toluene directly forms pyrene, without being first decomposed into smaller radicals. Less acetylene is therefore present in the gas phase and hence the HACA-pathway slows down. This is also shown in figure 3 , where with increasing amounts of toluene in the fuel mixture, the pathway for pyrene formation by reaction of two aromatic species gains significance.

Another mentionable observation involves the pyrenyl radicals in the soot precursor pool. While the mole fraction of these radicals is very low in the gas phase at lower temperatures $(<1800 \mathrm{~K})$, it increases with rising temperature, which may affect the extracted soot precursor pools at these temperatures. Furthermore, neither chrysene nor perylene showed high enough mole fractions in the gas phase for any soot precursor pool composition.

Common properties to all detected growth structures. At the end of the ReaxFF simulations, all structures that underwent some kind of growth reaction were analyzed. A total of 449 individual growth structures was obtained from all calculations run for the tested 128 soot precursor compositions. The abundancy of each generated structure was plotted against its molecular mass for all fuel mixtures, equivalence ratios and temperatures (Fig. 4). This plot is similar to experimental mass spectra distributions measured in the soot inception zone. ${ }^{42,69,89,90}$ The main peak at a molecular mass of $402 \mathrm{~g} / \mathrm{mol}$ notably matches the molecular formula of $\mathrm{C}_{32} \mathrm{H}_{18}$, which corresponds to the product of two pyrenyl radicals. As pyrene is 


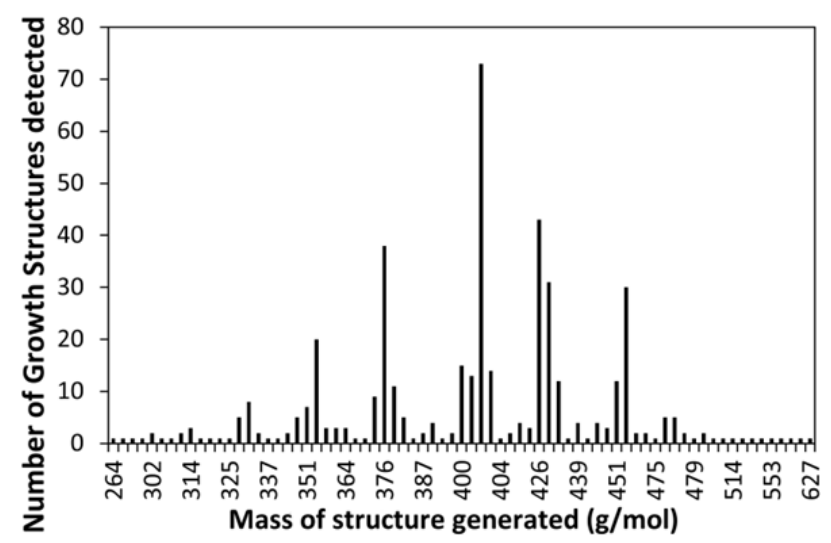

Figure 4. Mass distribution of all generated structures grown from soot precursors for all fuel mixtures, equivalence ratios and temperatures. The main peaks correspond to the following sum formula: $\mathrm{C}_{26} \mathrm{H}_{15}=327 \mathrm{~g} / \mathrm{mol} ; \mathrm{C}_{30} \mathrm{H}_{16}=376 \mathrm{~g} / \mathrm{mol} ; \mathrm{C}_{32} \mathrm{H}_{18}=402$ $\mathrm{g} / \mathrm{mol} ; \mathrm{C}_{34} \mathrm{H}_{18}=426 \mathrm{~g} / \mathrm{mol} ; \mathrm{C}_{36} \mathrm{H}_{20}=452 \mathrm{~g} / \mathrm{mol}$.

the most abundant species in the compositions, it is not surprising that the most prominent product corresponds to the reaction of two pyrene molecules. In fact, over $50 \%$ of the total structures generated had pyrene as a reactant and 100\% of these structures had either pyrene, pyrenyl radical or acetylenated pyrene as a reactant. This leads to the assumption that the precursor pool extracted from Raj's mechanism is missing possible other PAH than pyrene that can form in the gas-phase other. This is taken into account, but since pyrene is a good substitute for the general properties of PAH the results obtained can nonetheless be considered to be representative.

Figure 5 shows the number of $\mathrm{H}$-atoms present in the product molecule as a function of the number of $\mathrm{C}$-atoms. This figure puts forward that upon increasing carbon content (and thus molecular mass), the $\mathrm{H} / \mathrm{C}$ ratio converges to a value larger than 0.5. Again one can find that these plots are comparable to experimental studies in which $\mathrm{H} / \mathrm{C}$ ratios around 0.5 were found in the soot inception zone in experimental flames for the largest species. $42,69,89,90$

The generated structures possess, in average, between seven and eight aromatic rings. This finding is consistent with a HRTEM analysis by Botero et al., who estimated the number of rings of a fringe found in soot particles based on the fringe length. ${ }^{91}$ Furthermore, $18 \%$ of the structures include one or more rings with an odd number of $\mathrm{C}$-atoms, leading to a stress in the graphitic plane and as a result to a more bend structure. This finding is consistent with other modeling studies, ${ }^{92-94}$ as well as a recent atomic force microscopy study by Schulz et $\mathrm{al}^{40}$ on soot precursors in the inception regime, showing that odd-numbered rings are found in nascent soot particles. In general, all features observed by Schulz et al., i.e. linked aromatic moieties, aromatic moieties with sidechains and large $\mathrm{PAH}$ with 7 or more rings were reproduced by the present study. Furthermore, Adamson et al. showed in a recent mass spectra study that aliphatic links between aromatic moieties and also aliphatic sidechains are found in nascent soot particles. ${ }^{41}$ These features are also found in the structures created with our coupled Chemkin ReaxFF approach as $47 \%$ of the total structures generated exhibit sidechains, $36 \%$ of the total structures are aliphatically linked and $32 \%$ are directly linked.

Impact of combustion conditions on structural differences. The number of growth structures detected at the end of the

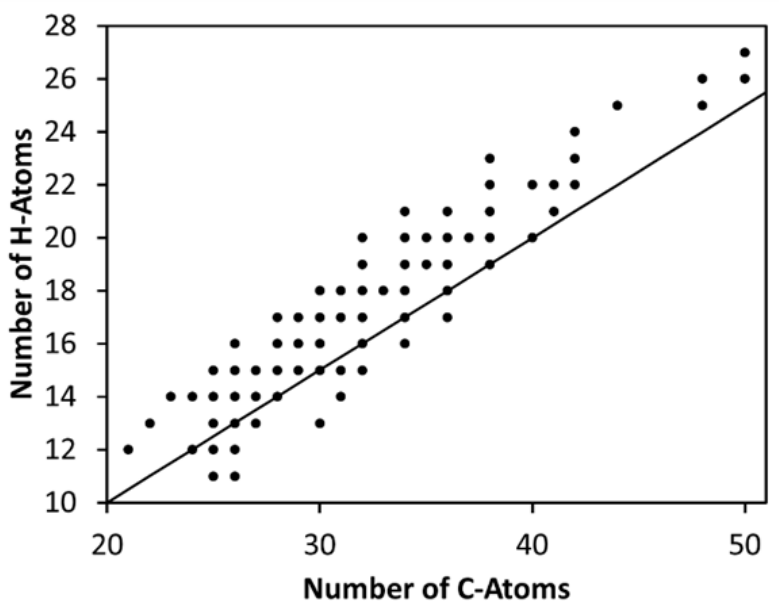

Figure 5. Number of $\mathrm{H}$-atoms over the number of $\mathrm{C}$-atoms found for all generated structures grown from soot precursors for all fuel mixtures, equivalence ratios and temperatures. The solid line depicts the values for an $\mathrm{H} / \mathrm{C}$ ratio of 0.5 .

ReaxFF calculations are averaged for the whole range of two parameters and varying the third parameter in Figures 6a-c. This is done in order to show the influence of the third parameter on the growth through, e.g. chemical dimerization or fragment addition. For example, Figure 6 a reports the detected growth structures averaged for the whole range of temperatures and equivalence ratios, at distinguished percentages of ndecane in the n-decane/toluene fuel mixture. This better illustrates the impact of soot precursor composition change resulting from one of the tested parameters and subsequently the bond formation between PAH.

While the average number of detected growth structures remains rather constant over the range of tested fuel mixtures and equivalence ratios, one can distinguish a linear increase of the growth structures detected with increasing temperature used in the Chemkin calculations. Since all molecular dynamics simulations are realized at $2500 \mathrm{~K}$, this increase must be attributed to changes in the composition resulting from the Chemkin calculations. Indeed, higher radical concentrations, e.g. pyrenyl radicals, are found with increasing temperatures, in line with the higher radical concentration found in precursor pools in experiments, thereby enhancing chemical growth. ${ }^{95,96}$ Moreover, the pyrenyl radicals are found to decompose in some cases into smaller resonance-stabilized radical species, which in turn can produce $\mathrm{PAH}$ radicals through $\mathrm{H}$ abstraction. The latter can then react with each other, or be involved in additional reactions with other PAH.

Another group of species that proved to contribute largely towards the reactivity are acetylenated pyrenes. These species may account for the difference between structures generated at $1400 \mathrm{~K}$ and $1600 \mathrm{~K}$. While the compositions obtained at 1400 $\mathrm{K}$ are dominated by pyrene, the compositions obtained at 1600 $\mathrm{K}$ are more diverse and also have higher numbers of acetylenated pyrene entities. Due to the presence of an acetylene side chain, a radical addition at the end of the sidechain is sterically less hindered than in the absence of a side chain. 


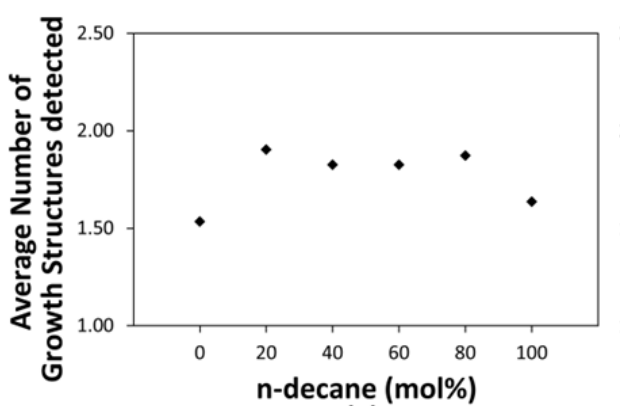

(a)

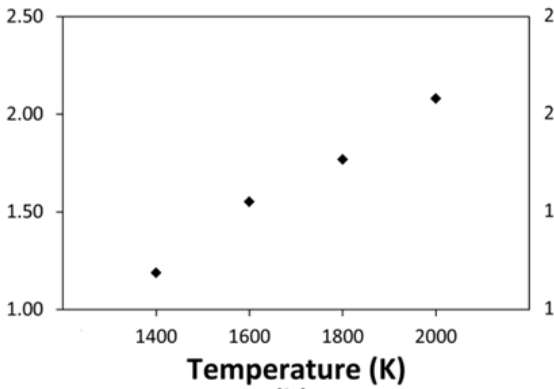

(b)

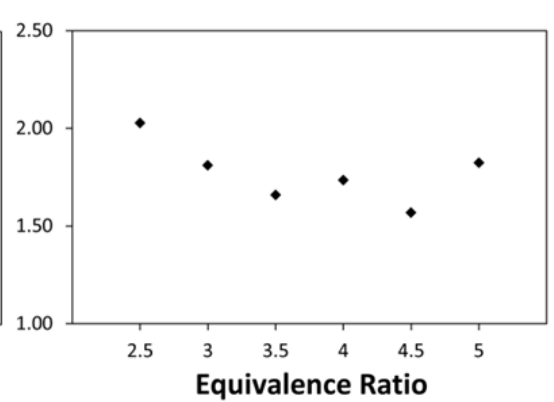

(c)

Figure 6. Average number of chemical growth products for all ReaxFF calculations as a function of (a) fuel composition, (b) temperature and (c) equivalence ratio.

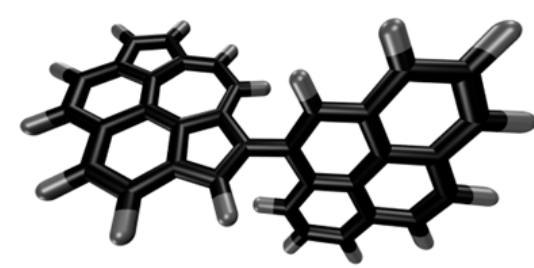

ADLH structure

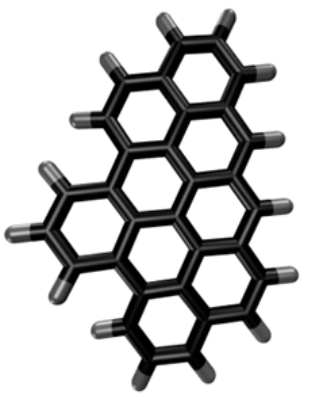

APPH structure

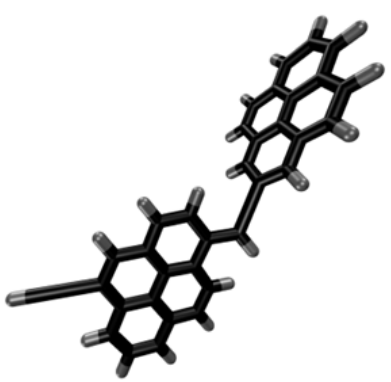

AALH structure

Figure 7. Representative structures of the three groups used to show their structural differentiation. Left: aromatic directly linked hydrocarbon structure; middle: aromatic pericondensed polycyclic hydrocarbon structure; right: aromatic aliphatically linked hydrocarbon structure.

All generated species from our MD simulations could be categorized into three main classes on basis of their chemical structure. The first class envelopes all structures with directly linked aromatic moieties. Structures exhibiting this feature are in the following referred to as aromatic directly linked hydrocarbon structures (ADLH). This means that the two aromatic pericondensed planes are directly linked to one another, without additional $\mathrm{C}$-atoms between the aromatic moieties. The second class assembles the molecules that exhibit one pericondensed polycyclic plane as main feature and are termed aromatic pericondensed polycyclic hydrocarbon structures (APPH). The third class comprises molecules exhibiting two or more aromatic moieties linked by aliphatic chains, in the following referred to as aromatic aliphatically linked hydrocarbons (AALH). Representatives of the structural different groups are depicted in figure 7.

The evolution of these three classes as a function of the fuel mixture is shown in figure 8. While there is no clear trend for the ADLH and APPH structures, there is a clear linear trend for the AALH structures. The formation of AALH structures increases with the aliphatic content of the fuel mixture. The findings of Adamson et al. ${ }^{41}$ strongly support the importance of aliphatic links between aromatic moieties in nascent soot particles, but their study did not span a range of fuel compositions.

The generated structures can also be classified according to the presence of aliphatic sidechains. The occurrence of aliphatic sidechains as a function of the fuel mixture composition is shown in Figure 9. The atomic force microscopy study of Schulz et al. shows that sidechains commonly occur in early soot structures. ${ }^{40}$ In addition, Adamson et al. found aliphatic sidechains in soot precursors using mass spectrometry. ${ }^{41}$
To study functional groups on soot surfaces experimentally, FT-IR spectroscopy has been previously used to probe the nature and content of $\mathrm{C}-\mathrm{H}$ functional groups. Using this approach Jaramillo et al. found that soot formed from pure aromatic fuels has a higher $\mathrm{sp}^{2} / \mathrm{sp}^{3}$ ratio (i.e. it contains less aliphatic C-H groups) than soot formed from aliphatic fuels. ${ }^{97}$ Interestingly, they also found that soot formed from mixtures of aliphatic and aromatic fuels have a $\mathrm{sp}^{2} / \mathrm{sp}^{3}$ ratio that is even smaller than the ratio for pure aliphatic fuels, and thus even contains more aliphatic $\mathrm{C}-\mathrm{H}$ groups than soot formed from pure aliphatic compounds, which has also been confirmed in a study by Liu et al. ${ }^{98}$

In our study the average number of carbon atoms found in a link between PAH is two, corresponding to an ethyl bridge, and the average number of carbon atoms found in a sidechain is four. The average ratio of carbon atoms present in a sidechain or bridge to carbon atoms in pericondensed rings is 0.13 for soot structures formed by pure $n$-decane, and 0.12 for soot structures formed by pure toluene. Soot formed from mixtures of n-decane and toluene in general exhibit a higher ratio of "sidechain/bridge" carbon to "pericondensed rings" carbon than the pure compounds.

Hence, our results are in line with the FT-IR studies of Jaramillo et al. and Liu et al. Yet, a direct comparison of our results with the FT-IR studies is not straightforward. In the FT-IR studies the ratio of $\mathrm{sp}^{3}$ (aliphatic) carbon to $\mathrm{sp}^{2}$ carbon in pericondensed rings is measured by comparing the relative peak heights of the $\mathrm{C}=\mathrm{C}$ stretching mode and the aliphatic $\mathrm{C}$ $\mathrm{H}$ stretching mode, since the aromatic $\mathrm{C}-\mathrm{H}$ stretching modes and the acetylenic $\mathrm{C}-\mathrm{H}$ stretching modes are "hidden" behind the broad O-H stretching mode. ${ }^{99}$ However, the sidechains in this study might contain unsaturations and these could not be distinguished from the aromatic vibrations in the FT-IR stud 


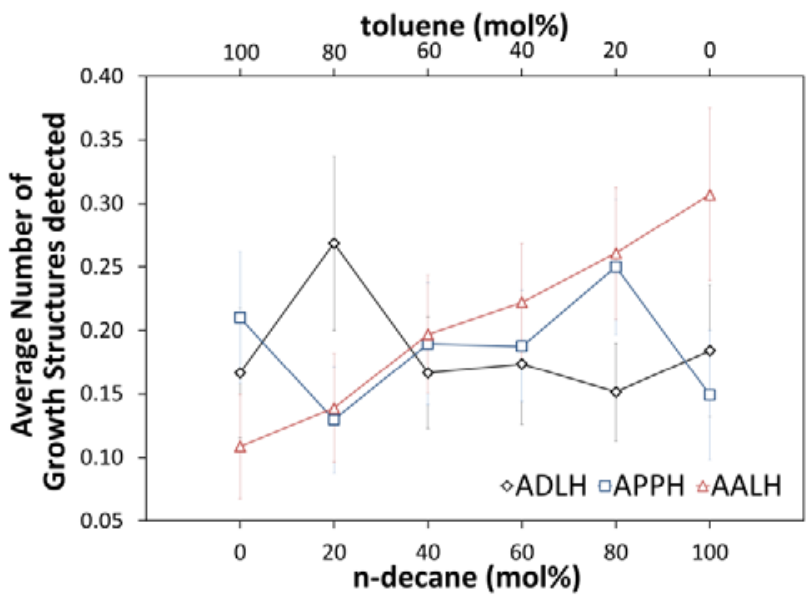

Figure 8. The average number of grown soot structures through bond formation for all calculations at all temperatures, equivalence ratios and fuel mixtures with different structural features, plotted as a function of the fuel mixture. The vertical bars represent the respective errors. An explanation why the sum of average growth structures (like in Figure 9) does not necessarily match the average value reported in Figure 6 is given in the supplementary material

ies. Interestingly, in Raman spectroscopy studies, Le et al. found a peak corresponding to sp-hybridized carbon structures in soot formed from low pressure ethylene soot, indicating the presence of such poly-yne sidechains, ${ }^{100}$ which were also detected in our theoretical study.

In the present study, the correlation between the fuel composition and the growth structures containing aliphatic links and/or sidechains is related to the soot precursor compositions extracted from Chemkin being more diverse for aliphatic-rich fuels than for aromatic-rich fuels (cf. Figure 2). As a result of the higher diversity and the higher amount of PAH possessing a sidechain, reactions occurring on carbon atoms in a sidechain become more probable. Furthermore, after a bond formation between two PAH has occurred the growth structure is more likely to possess a sidechain, because one of the reactants already possessed a sidechain. The established correlation between the (aliphatic) decane content in the fuel mixture and the detected number of growth structures containing aliphatically linked structures and/or sidechains thus seems plausible, since the concentrations of aliphatic molecules and aliphatic radicals are higher for aliphatic fuels than for aromatic fuels in the gas phase during combustion. Hence, the addition of these species to PAH radicals occurs more frequently.

Analysis of the most common reaction pathways. Based on the above described structural differentiation of ADLH, APPH and AALH structures, one can investigate the most common reaction pathways that lead to these structures. In this context it is important to note that all three structure types have a common initiation reaction, i.e., the production of radicals through the dissociation of smaller species from the PAH, thereby stressing its importance. Apart from $\mathrm{C}-\mathrm{H}$ dissociation, the dissociation of an acetylenyl-radical from an acetylenated PAH also occurs frequently. Furthermore, resonance stabilized radicals, which have been shown to play a crucial role in PAH and soot formation, 39 have been detected during the bond formation between PAH. However, in this. study no increased reactivity from these species could be detected.

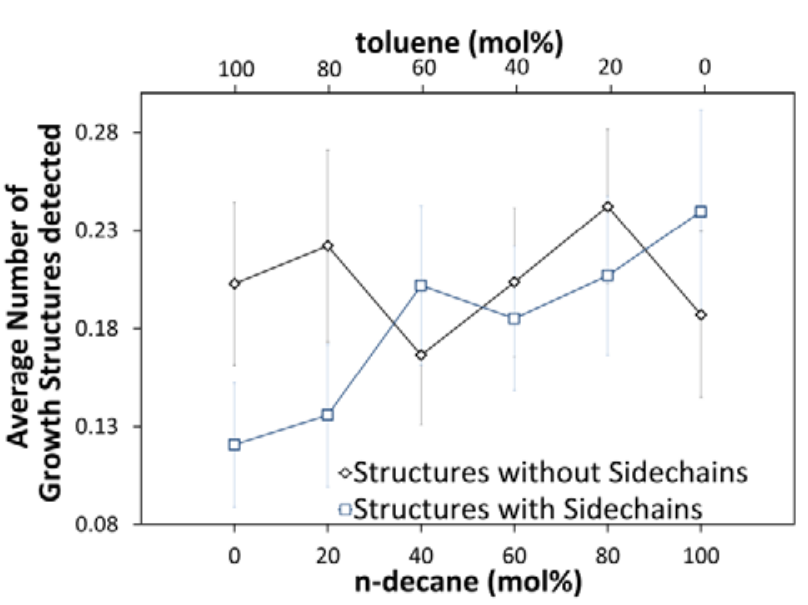

Figure 9. The average number of detected growth structures for all calculations at all temperatures, equivalence ratios and fuel mixtures with and without sidechains, plotted as a function of the fuel mixture. The vertical bars represent the respective errors.

The ADLH structures are created by a direct addition of one PAH radical to either another PAH radical or a non-radical $\mathrm{PAH}$, usually followed by an H-dissociation, or occasionally by a $\mathrm{C}_{2} \mathrm{H}$-dissociation. A general representation of the common reaction pathway is depicted in figure 8 , where the ADLH structure is highlighted in red. In some cases, an addition to a PAH with a sidechain at the position of the sidechain could be observed. However, this pathway is far less common due to steric hindrance.

Under the conditions investigated, the most commonly encountered reaction pathways for AALH structures are twofold. The pathway is either initiated by the addition of a $\mathrm{PAH}$ radical to the sidechain of another PAH or a direct addition of a $\mathrm{PAH}$ radical to another PAH followed by a ring opening, hence leading to an aliphatic link between the two aromatic sheets. Since the presence of PAH with aliphatic side chains in the initial compositions is less marked, the ring openings of ADLH structures are more frequently observed than direct addition to the aliphatic side chain of another PAH. For this reason, one of the aromatic moieties of the AALH structures consists of less than 4 rings. A general schematic representation of the two pathways observed is depicted in figure 8, where the AALH structure is highlighted in green.

The unstable AALH structures further evolve into APPH structures through rearrangement, leading to ring closure and the production of one pericondensed plane. Ring opening and rearrangement reactions have been known to play a role in the growth and stabilization on graphene and PAH surfaces. ${ }^{93,101}$ For a better understanding a general diagram of the growth pathways of APPH structures is depicted in figure 8, in which the APPH structure is highlighted in blue. In principle, a direct transition from an ADLH structure to an APPH structure is also possible in some cases. This was also observed during the simulations. This reaction was less frequent, however, compared to the route through a ring opening leading to an AALH structure first. 


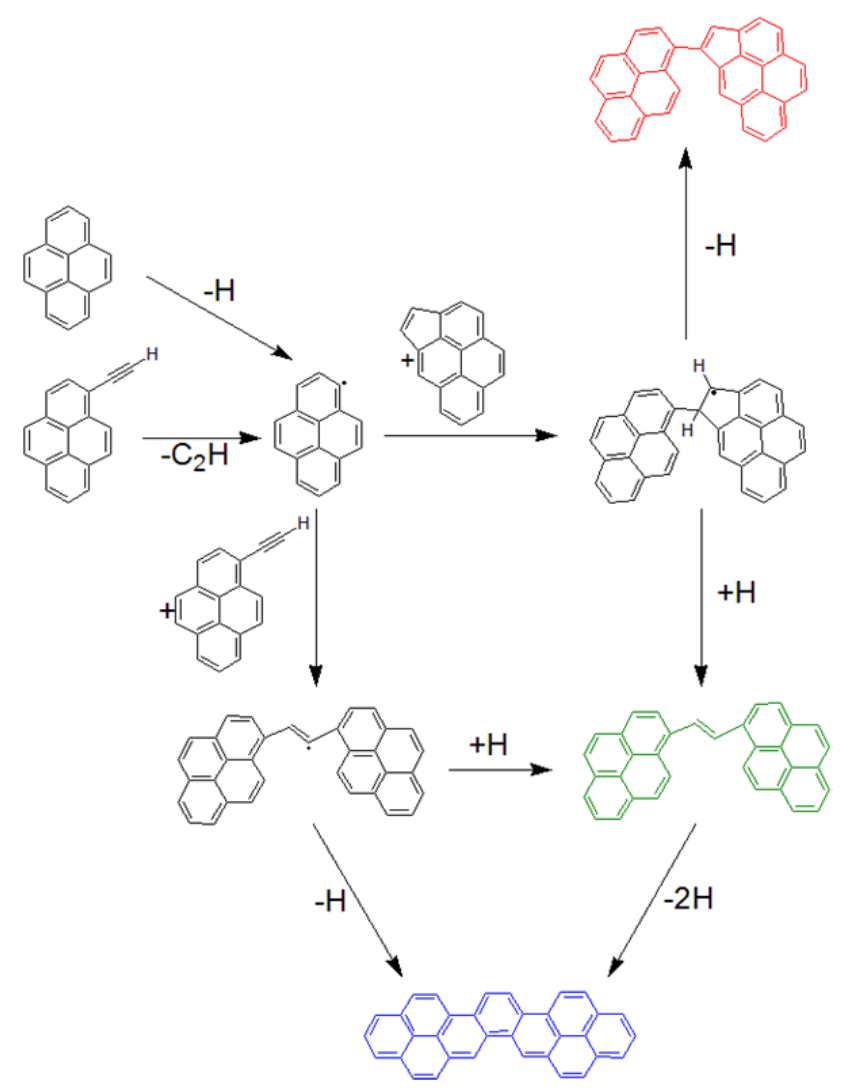

Figure 10. A schematic depiction of the most representative reaction pathways for the most commonly found structures. The product for each structural group are highlighted in color. In order to help comprehension only forward reactions are shown. Videos of an example reaction pathway for each of the different structural groups can be found in the supporting material.

As shown in figure 4 the range of molecular masses is broad, ranging from 264 to $627 \mathrm{~g} / \mathrm{mol}$. Hence, also the growth through smaller species would have to take place and was observed during the simulations. These species were generated by the dissociation of small, aliphatic species from PAH that either already possess a side chain or where the side chain is formed after a ring opening. The latter route also leads to smaller-sized radicals and resonance-stabilized radicals. These species influence the growth by addition to PAH leading to growth products of different structures and masses. Figure 8 hence generalizes the most common reaction pathways. It is also important to note that each reaction is in principle reversible in the molecular dynamics simulations, but they are depicted only as forward reaction for better comprehension in figure 8 . Therefore, a ring opening can be followed by a ring closure or a dissociation reaction by a recombination and vice versa. Furthermore, it was found that H-migration plays a significant role in the bond formation process. Rapid migrations of hydrogen atoms on the PAH and assisted ring opening and rearrangement reactions could be observed. This finding is consistent with earlier findings of Frenklach et al. ${ }^{102}$ who observed that similar migration reactions also assist the growth of PAH through addition of smaller species.

Short videos of the most important observed reaction pathways of the different structural groups during the molecular dynamics simulation are provided in the Supporting Material.

\section{Conclusions}

In this theoretical study the ability of a multiscale modeling methodology was assessed to investigate bond formation of soot precursors as a function of thermodynamic and chemical conditions on the structural features of these reaction products. This approach is based on PAH concentrations generated from detailed chemical kinetic mechanisms and reactive force field molecular dynamics.

The structures obtained by our simulations compare well with those obtained from experiments, and thus validates our theoretical approach to simulate PAH growth by chemical bond formation in the selected conditions. Due to selection criteria of the molecules generated by the macroscopic gas-phase kinetic calculations, the molecular dynamics calculations with ReaxFF calculations focus on relatively large PAH to investigate the growth through bond formation. Hence, most of the structures presented do not involve products of the interaction of PAH with smaller aromatic or aliphatic species. In addition, small radicals and radicals in general have been found to aid soot growth, but this needs to be investigated further. Furthermore, structural changes due to oxidation or oxygenated species have not yet been considered in the current approach. Nonetheless, the comparison clearly indicates that the methodology is able to reproduce species with properties similar to those found in experimental flames and that bond formation between $\mathrm{PAH}$ is a process that needs to be taken into account in soot inception.

Furthermore, the resulting structures where lumped into classes based on structurally different features and correlated to the fuel composition. It is concluded that soot precursor molecules possess more aliphatic links if the aliphatic content of the parent fuel is higher. The same correlation could be found for aliphatic side chains to the aliphatic content of the parent fuel used to generate the initial precursor pool. While Adamson et al. provided evidence for the presence of these aliphatic sidechains and links in nascent soot particles using mass spectroscopy, ${ }^{41}$ an impact of the fuel composition on these aliphatic moieties in nascent soot particles reported here, remains to be investigated experimentally.

The most frequently observed reaction pathways were analyzed and the most common structures are in general found to be achieved through analogous reactions. In addition, it was found that H-migration often assists the bond formation, leading to ring-opening and rearrangements inside the reaction product that leads to stabilization.

This study shows the importance to include bond formation between PAH in the soot inception mechanism. By taking into account chemical bond formation between $\mathrm{PAH}$, we were able to produce physical properties found in soot inception. Additionally, a wide variety of structures could be generated having a large range of structural features, that could also be found in a structural study at the atomistic level. ${ }^{40}$ This demonstrates that bond formation between PAH can lead to a variety of products and thus must be included into the modeling of soot inception and soot growth, as it would enable the description of the rampant growth of soot precursors that cannot be achieved by stepwise addition of smaller species to PAHs.

\section{ASSOCIATED CONTENT}

Supporting Information 
Description of the equivalence ratio, a rate analysis and pathway analysis of Raj's mechanism for the PAH considered and a display of the extracted soot precursor compositions (Word file). Example reaction pathway for ADLH structures (AVI file). Example reaction pathway for APPH structures (AVI file). Example reaction pathway for AALH structures (AVI file).

\section{AUTHOR INFORMATION}

Corresponding Author

E-mail: theodorus.de-bruin@ifpen.fr

The manuscript was written through contributions of all authors. All authors have given approval to the final version of the manuscript.

\section{ACKNOWLEDGMENT}

This project has received funding from the European Union Horizon 2020 Research and Innovation program. Grant Agreement No 675528 for the IPPAD project.

\section{ABBREVIATIONS}

PAH Polyaromatic hydrocarbon

BSU basic structural unit

ROP Rate of production

ADLH Aromatic directly linked hydrocarbon

AALH Aromatic aliphatically linked hydrocarbon

APPH Aromatic pericondensed polycyclic hydrocarbon

\section{REFERENCES}

(1) Oberdörster, G.; Oberdörster, E.; Oberdörster, J. Nanotoxicology: An Emerging Discipline Evolving from Studies of Ultrafine Particles. Environ. Health Perspect. 2005, 113, 823-839.

(2) Kim, K.-H.; Kabir, E.; Kabir, S. A review on the human health impact of airborne particulate matter. Environ. Int. 2015, 74, 136143.

(3) Jacobson, M. Z. Short-term effects of controlling fossil-fuel soot, biofuel soot and gases, and methane on climate, Arctic ice, and air pollution health. J. Geophys. Res. 2010, 115, D14209.

(4) Bond, T. C.; Doherty, S. J.; Fahey, D. W.; Forster, P. M.; Berntsen, T.; DeAngelo, B. J.; Flanner, M. G.; Ghan, S.; Kärcher, B.; Koch, D. et al. Bounding the role of black carbon in the climate system: A scientific assessment. J. Geophys. Res. Atmos. 2013, 118, $5380-5552$.

(5) Liu, L.; Mishchenko, M. I.; Patrick Arnott, W. A study of radiative properties of fractal soot aggregates using the superposition Tmatrix method. J. Quant. Spectrosc. Radiat. Transf. 2008, 109, 26562663.

(6) Vander Wal, R. L. Soot Nanostructure: Definition, Quantification and Implications. SAE Transactions 2005, 114, 429-436.

(7) Vander Wal, R. L.; Tomasek, A. J. Soot nanostructure: dependence upon synthesis conditions. Combust. Flame 2004, 136, 129-140.

(8) Yehliu, K.; Vander Wal, R. L.; Armas, O.; Boehman, A. L. Impact of fuel formulation on the nanostructure and reactivity of diesel soot. Combust. Flame 2012, 159, 3597-3606.

(9) Vander Wal, R. L.; Yezerets, A.; Currier, N. W.; Kim, D. H.; Wang, C. M. HRTEM Study of diesel soot collected from diesel particulate filters. Carbon 2007, 45, 70-77.

(10) Ye, P.; Sun, C.; Lapuerta, M.; Agudelo, J.; Vander Wal, R.; Boehman, A. L.; Toops, T. J.; Daw, S. Impact of rail pressure and biodiesel fueling on the particulate morphology and soot nanostructures from a common-rail turbocharged direct injection diesel engine. Int. J. Engine Res. 2014, 17, 193-208.

(11) Vander Wal, R. L.; Mueller, C. J. Initial Investigation of Effects of Fuel Oxygenation on Nanostructure of Soot from a DirectInjection Diesel Engine. Energy Fuels 2006, 20, 2364-2369.

(12) Vander Wal, R. L.; Tomasek, A. J. Soot oxidation: Dependence upon initial nanostructure. Combust. Flame 2003, 134, 1-9.
(13) Gaddam, C. K.; Vander Wal, R. L.; Chen, X.; Yezerets, A.; Kamasamudram, K. Reconciliation of carbon oxidation rates and activation energies based on changing nanostructure. Carbon 2016, $98,545-556$.

(14) Violi, A. Effects of Combustion-Generated Nanoparticles on Cellular Membranes. Combust. Sci. Technol. 2016, 188, 769-775.

(15) Lighty, J. S.; Veranth, J. M.; Sarofim, A. F. Combustion Aerosols: Factors Governing Their Size and Composition and Implications to Human Health. J. the Air Waste Manag. Assoc. 2000, 50, $1565-1618$.

(16) Appel, J.; Bockhorn, H.; Frenklach, M. Kinetic modeling of soot formation with detailed chemistry and physics: laminar premixed flames of C2 hydrocarbons. Combust. Flame 2000, 121, 122-136.

(17) Balthasar, M.; Mauss, F.; Knobel, A.; Kraft, M. Detailed modeling of soot formation in a partially stirred plug flow reactor. Combust. Flame 2002, 128, 395-409.

(18) Mosbach, S.; Celnik, M. S.; Raj, A.; Kraft, M.; Zhang, H. R.; Kubo, S.; Kim, K.-O. Towards a detailed soot model for internal combustion engines. Combust. Flame 2009, 156, 1156-1165.

(19) C. A. Schuetz and M. Frenklach. Nucleation of Soot: Molecular Dynamics Simulation of Pyrene Dimerizaton. Proc. Comb. Inst. 2002, 29, 2307-2314.

(20) Zhao, B.; Yang, Z.; Li, Z.; Johnston, M. V.; Wang, H. Particle size distribution function of incipient soot in laminar premixed ethylene flames: effect of flame temperature. Proc. Comb. Inst. 2005, 30, 1441-1448.

(21) Singh, J.; Patterson, R. I.A.; Kraft, M.; Wang, H. Numerical simulation and sensitivity analysis of detailed soot particle size distribution in laminar premixed ethylene flames. Combust. Flame 2006, $145,117-127$

(22) Wang, H. Formation of nascent soot and other condensedphase materials in flames. Proc. Comb. Inst. 2011, 33, 41-67.

(23) Miller, J. H. Aromatic excimers: evidence for polynuclear aromatic hydrocarbon condensation in flames. Proc. Comb. Inst. 2005 , 30, 1381-1388.

(24) Herdman, J. D.; Miller, J. H. Intermolecular potential calculations for polynuclear aromatic hydrocarbon clusters. J. Phys. Chem. A 2008, 112, 6249-6256.

(25) Sabbah, H.; Biennier, L.; Klippenstein, S. J.; Sims, I. R.; Rowe, B. R. Exploring the Role of PAHs in the Formation of Soot: Pyrene Dimerization. J. Phys. Chem. Lett. 2010, 1, 2962-2967.

(26) Totton, T. S.; Misquitta, A. J.; Kraft, M. A quantitative study of the clustering of polycyclic aromatic hydrocarbons at high temperatures. Phys. Chem. Chem. Phys. 2012, 14, 4081-4094.

(27) Elvati, P.; Violi, A. Thermodynamics of poly-aromatic hydrocarbon clustering and the effects of substituted aliphatic chains. Proc. Comb. Inst. 2013, 34, 1837-1843.

(28) Totton, T. S.; Misquitta, A. J.; Kraft, M. A First Principles Development of a General Anisotropic Potential for Polycyclic Aromatic Hydrocarbons. J. Chem. Theory Comp. 2010, 6, 683-695.

(29) Totton, T. S.; Misquitta, A. J.; Kraft, M. A transferable electrostatic model for intermolecular interactions between polycyclic aromatic hydrocarbons. Chem. Phys. Lett. 2011, 510, 154-160.

(30) Mouton, T.; Mercier, X.; Desgroux, P. Evidence of Nucleation Flames: A Valuable Tool for the Study of Soot Particles Inception, 7th European Combustion Meeting, 2015, Hungary.

(31) Chung, S.-H.; Violi, A. Peri-condensed aromatics with aliphatic chains as key intermediates for the nucleation of aromatic hydrocarbons. Proc. Comb. Inst. 2011, 33, 693-700.

(32) Eaves, N. A.; Dworkin, S. B.; Thomson, M. J. The importance of reversibility in modeling soot nucleation and condensation processes. Proc. Comb. Inst. 2015, 35, 1787-1794

(33) Eaves, N. A.; Dworkin, S. B.; Thomson, M. J. Assessing relative contributions of PAHs to soot mass by reversible heterogeneous nucleation and condensation. Proc. Comb. Inst. 2017, 36, 935-945.

(34) Kholghy, M. R.; Kelesidis, G. A.; Pratsinis, S. E. Reactive polycyclic aromatic hydrocarbon dimerization drives soot nucleation. Phys. Chem. Chem. Phys. 2018, 20, 10926-10938.

(35) Kholghy, M. R.; Eaves, N. A.; Veshkini, A.; Thomson, M. J. The role of reactive PAH dimerization in reducing soot nucleation reversibility. Proc. Comb. Inst. 2018, 37, 1003-1011. 
(36) Elvati, P.; Dillstrom, V. T.; Violi, A. Oxygen driven soot formation. Proc. Comb. Inst. 2017, 36, 825-832.

(37) Johansson, K. O.; Dillstrom, T.; Elvati, P.; Campbell, M. F.; Schrader, P. E.; Popolan-Vaida, D. M.; Richards-Henderson, N. K.; Wilson, K. R.; Violi, A.; Michelsen, H. A. Radical-radical reactions, pyrene nucleation, and incipient soot formation in combustion. Proc. Comb. Inst. 2017, 36, 799-806.

(38) Lowe, J. S.; Lai, J. Y.W.; Elvati, P.; Violi, A. Towards a predictive model for polycyclic aromatic hydrocarbon dimerization propensity. Proc. Comb. Inst. 2015, 35, 1827-1832.

(39) Johansson, K. O.; Head-Gordon, M. P.; Schrader, P. E.; Wilson, K. R.; Michelsen, H. A. Resonance-stabilized hydrocarbonradical chain reactions may explain soot inception and growth. Science 2018, 361, 997.

(40) Schulz, F.; Commodo, M.; Kaiser, K.; Falco, G. de; Minutolo, P.; Meyer, G.; D`Anna, A.; Gross, L. Insights into incipient soot formation by atomic force microscopy. Proc. Comb. Inst. 2018, 37, $885-892$.

(41) Adamson, B. D.; Skeen, S. A.; Ahmed, M.; Hansen, N. Detection of Aliphatically Bridged Multi-Core Polycyclic Aromatic Hydrocarbons in Sooting Flames with Atmospheric-Sampling HighResolution Tandem Mass Spectrometry. J. Phys. Chem. A. 2018, 122, 9338-9349.

(42) Cain, J.; Laskin, A.; Kholghy, M. R.; Thomson, M. J.; Wang, H. Molecular characterization of organic content of soot along the centerline of a coflow diffusion flame. Phys. Chem. Chem. Phys. 2014, 16, 25862-25875.

(43) D'Anna, A.; Violi, A. A kinetic model for the formation of aromatic hydrocarbons in premixed laminar flames. Proc. Comb. Inst. 1998, 27, 425-433.

(44) Violi, A.; D’Anna, A.; D'Alessio, A. Modeling of particulate formation in combustion and pyrolysis. Chem. Eng. Sci. 1999, 54, 3433-3442.

(45) D'Anna, A.; Violi, A. Detailed Modeling of the Molecular Growth Process in Aromatic and Aliphatic Premixed Flames. Energy Fuels 2005, 19, 79-86.

(46) Lai, J. Y. W. Stochastic Simulation of Carbonaceous Nanoparticle Precursor Formation in Combustion. Dissertation, University of Michigan 2014

(47) van Duin, Adri C. T.; Dasgupta, S.; Lorant, F.; Goddard, W. A. ReaxFF: A Reactive Force Field for Hydrocarbons. J. Phys. Chem. A 2001, 105, 9396-9409.

(48) Zhang, C.; Zhang, C.; Ma, Y.; Xue, X. Imaging the C black formation by acetylene pyrolysis with molecular reactive force field simulations. Phys. Chem. Chem. Phys. 2015, 17, 11469-11480.

(49) Xue, X.; Meng, L.; Ma, Y.; Zhang, C. Molecular Reactive Force-Field Simulations on the Carbon Nanocavities from Methane Pyrolisis. J. Phys. Chem. C 2017, 121, 7502-7513.

(50) Han, S.; Li, X.; Nie, F.; Zheng, M.; Liu, X.; Guo, L. Revealing the Initial Chemistry of Soot Nanoparticle Formation by ReaxFF Molecular Dynamics Simulations. Energy Fuels 2017, 31, 84348444

(51) Mao, Q.; van Duin, A. C.T.; Luo, K. H. Formation of incipient soot particles from polycyclic aromatic hydrocarbons: A ReaxFF molecular dynamics study. Carbon 2017, 121, 380-388.

(52) Mao, Q.; Ren, Y.; Luo, K. H.; van Duin, Adri C. T. Dynamics and kinetics of reversible homo-molecular dimerization of polycyclic aromatic hydrocarbons. J. Chem. Phys. 2017, 147, 244305.

(53) Mao, Q.; Hou, D.; Luo, K. H.; You, X. Dimerization of Polycyclic Aromatic Hydrocarbon Molecules and Radicals under Flame Conditions. J. Phys. Chem. A 2018, 122, 8701-8708.

(54) Mao, Q.; Luo, K. H. Trace metal assisted polycyclic aromatic hydrocarbons fragmentation, growth and soot nucleation. Proc. Comb. Inst. 2019, 37, 1023-1030.

(55) Yuan, H.; Kong, W.; Liu, F.; Chen, D. Study on soot nucleation and growth from PAHs and some reactive species at flame temperatures by ReaxFF molecular dynamics. Chem. Eng. Sci. 2018, 195, $748-757$.

(56) Wang, H. Formation of nascent soot and other condensedphase materials in flames. Proc. Comb. Inst. 2011, 33, 41-67.

(57) CHEMKIN-PRO; Reaction Design: San Diego, 2013.
(58) Raj, A.; Prada, I. D. C.; Amer, A. A.; Chung, S. H. A reaction mechanism for gasoline surrogate fuels for large polycyclic aromatic hydrocarbons. Combust. Flame 2012, 159, 500-515.

(59) Park, S.; Wang, Y.; Chung, S. H.; Sarathy, S. M. Compositional effects on PAH and soot formation in counterflow diffusion flames of gasoline surrogate fuels. Combust. Flame 2017, 178, 46-60.

(60) Dworkin, S. B.; Zhang, Q.; Thomson, M. J.; Slavinskaya, N. A.; Riedel, U. Application of an enhanced PAH growth model to soot formation in a laminar coflow ethylene/air diffusion flame. Combust. Flame 2011, 158, 1682-1695.

(61) Keita, M.; Nicolle, A.; Bakali, A. E. A wide range kinetic modeling study of PAH formation from liquid transportation fuels combustion. Combust. Flame 2016, 174, 50-67.

(62) An, Y.-z.; Teng, S.-p.; Pei, Y.-q.; Qin, J.; Li, X.; Zhao, H. An experimental study of polycyclic aromatic hydrocarbons and soot emissions from a GDI engine fueled with commercial gasoline. Coal Structure 92 2016, 164, 160-171.

(63) Shao, C.; Wang, H.; Atef, N.; Wang, Z.; Chen, B.; Almalki, M.; Zhang, Y.; Cao, C.; Yang, J.; Sarathy, S. M. Polycyclic aromatic hydrocarbons in pyrolysis of gasoline surrogates (n-heptane/isooctane/toluene). Proc. Comb. Inst. 2019, 37, 993-1001.

(64) Raj, A.; Al Rashidi, M. J.; Chung, S. H.; Sarathy, S. M. PAH Growth Initiated by Propargyl Addition: Mechanism Development and Computational Kinetics. J. Phys. Chem. A 2014, 118, 2865-2885.

(65) Wang, Y.; Raj, A.; Chung, S. H. A PAH growth mechanism and synergistic effect on PAH formation in counterflow diffusion flames. Combust. Flame 2013, 160, 1667-1676.

(66) He, Z.; Zhou, K.; Xiao, M.; Wei, F. Simulation of Soot Size Distribution in a Counterflow Flame, 2019.851+02:00, 13.

(67) Kamimoto, T.; Bae, M.-h. High Combustion Temperature for the Reduction of Particulate in Diesel Engines; SAE International, 1988.

(68) Pischinger F.; Schulte H.; Hansen J. Die Zukunft des Dieselmotors: Grundlagen und Entwicklungslinien des dieselmotorischen Brennverfahren, 714th ed.; VDI-Berichte: Düsseldorf, 1988.

(69) Desgroux, P.; Faccinetto, A.; Mercier, X.; Mouton, T.; Aubagnac Karkar, D.; El Bakali, A. Comparative study of the soot formation process in a "nucleation" and a "sooting" low pressure premixed methane flame. Combust. Flame 2017, 184, 153-166.

(70) Ono, K.; Matsukawa, Y.; Dewa, K.; Watanabe, A.; Takahashi, K.; Saito, Y.; Matsushita, Y.; Aoki, H.; Era, K.; Aoki, T. et al. Formation mechanisms of soot from high-molecular-weight polycyclic aromatic hydrocarbons. Combust. Flame 2015, 162, 2670-2678.

(71) Shukla, B.; Susa, A.; Miyoshi, A.; Koshi, M. In Situ Direct Sampling Mass Spectrometric Study on Formation of Polycyclic Aromatic Hydrocarbons in Toluene Pyrolysis. J. Phys. Chem. A 2007 , $111,8308-8324$

(72) Bagley, S. P.; Wornat, M. J. Identification of Five- to SevenRing Polycyclic Aromatic Hydrocarbons from the Supercritical Pyrolysis of n-Decane. Energy Fuels 2011, 25, 4517-4527.

(73) Jia, Z.; Huang, H.; Zhou, W.; Qi, F.; Zeng, M. Experimental and Modeling Investigation of n-Decane Pyrolysis at Supercritical Pressures. Energy Fuels 2014, 28, 6019-6028.

(74) Norinaga, K.; Deutschmann, O.; Saegusa, N.; Hayashi, J.-i. Analysis of pyrolysis products from light hydrocarbons and kinetic modeling for growth of polycyclic aromatic hydrocarbons with detailed chemistry. J. Anal. Appl. Pyrolysis 2009, 86, 148-160.

(75) te Velde, G.; Bickelhaupt, F. M.; Baerends, E. J.; Fonseca Guerra, C.; van Gisbergen, S. J. A.; Snijders, J. G.; Ziegler, T. Chemistry with ADF. J. Comput. Chem. 2001, 22, 931-967.

(76) Chenoweth, K.; van Duin, Adri C T; Goddard, W. A. 3. ReaxFF reactive force field for molecular dynamics simulations of hydrocarbon oxidation. J. Phys. Chem. A 2008, 112, 1040-1053.

(77) Jin, H.; Xu, B.; Li, H.; Ku, X.; Fan, J. Numerical investigation of coal gasification in supercritical water with the ReaxFF molecular dynamics method. Int. J. Hydrog. Energy 2018, 43, 20513-20524.

(78) Chen, Z.; Sun, W.; Zhao, L. Combustion Mechanisms and Kinetics of Fuel Additives: A ReaxFF Molecular Simulation. Energy Fuels 2018, 32, 11852-11863.

(79) Jin, H.; Wu, Y.; Guo, L.; Su, X. Molecular dynamic investigation on hydrogen production by polycyclic aromatic hydrocarbon 
gasification in supercritical water. Int. J. Hydrog. Energy 2016, 41, 3837-3843.

(80) Castro-Marcano, F.; Kamat, A. M.; Russo Jr., M. F.; van Duin, A. C.T.; Mathews, J. P. Combustion of an Illinois No. 6 coal char simulated using an atomistic char representation and the ReaxFF reactive force field. Combust. Flame 2012, 159, 1272-1285.

(81) Zheng, M.; Li, X.; Liu, J.; Guo, L. Initial Chemical Reaction Simulation of Coal Pyrolysis via ReaxFF Molecular Dynamics. Energy Fuels 2013, 27, 2942-2951.

(82) Zheng, M.; Li, X.; Liu, J.; Wang, Z.; Gong, X.; Guo, L.; Song, W. Pyrolysis of Liulin Coal Simulated by GPU-Based ReaxFF MD with Cheminformatics Analysis. Energy Fuels 2014, 28, 522-534.

(83) Naber, J. D.; Siebers, D. L. Effects of Gas Density and Vaporization on Penetration and Dispersion of Diesel Sprays; SAE International, 1996.

(84) Inal, F.; Senkan, S. M. Effects of equivalence ratio on species and soot concentrations in premixed n-heptane flames. Combust. Flame 2002, 131, 16-28.

(85) Richter, H.; Howard, J.B. Formation of polycyclic aromatic hydrocarbons and their growth to soot - a review of chemical reaction pathways. Prog. Energy Combust. Sci. 2000, 26, 565-608.

(86) Frenklach, M.; Wang, H. Detailed modeling of soot particle nucleation and growth. Proc. Comb. Inst. 1991, 23, 1559-1566.

(87) Frenklach, M.; Clary, D. W.; Gardiner, W. C.; Stein, S. E. Detailed kinetic modeling of soot formation in shock-tube pyrolysis of acetylene. Proc. Comb. Inst. 1985, 20, 887-901.

(88) Wang, H.; Frenklach, M. Calculations of Rate Coefficients for the Chemically Activated Reactions of Acetylene with Vinylic and Aromatic Radicals. J. Phys. Chem. 1994, 98, 11465-11489.

(89) Irimiea, C.; Faccinetto, A.; Mercier, X.; Ortega, I.-K.; Nuns, N.; Therssen, E.; Desgroux, P.; Focsa, C. Unveiling trends in soot nucleation and growth: When secondary ion mass spectrometry meets statistical analysis. Carbon 2019, 144, 815-830.

(90) Apicella, B.; Carpentieri, A.; Alfè, M.; Barbella, R.; Tregrossi, A.; Pucci, P.; Ciajolo, A. Mass spectrometric analysis of large PAH in a fuel-rich ethylene flame. Proc. Comb. Inst. 2007, 31, 547-553.

(91) Botero, M.; Sheng, Y.; Akroyd, J.; Martin, J.; Dreyer, J.; Yang, W. M.; Kraft, M. Internal structure of soot particles in a diffusion flame. Carbon 2019, 141, 635-642.
(92) Johansson, K. O; Dillstrom, T.; Monti, M.; El Gabaly, F.; Campbell, M. F.; Schrader, P. E.; Popolan-Vaida, D. M.; RichardsHenderson, N. K.; Wilson, K. R.; Violi, A. et al. Formation and emission of large furans and oxygenated hydrocarbons from flames. Proc. Natl. Acad. Sci. USA 2016, 113, 8374-8379.

(93) Whitesides, R.; Domin, D.; Salomon-Ferrer, R.; Lester, W. A. JR; Frenklach, M. Graphene layer growth chemistry: five- and sixmember ring flip reaction. J. Phys. Chem. A 2008, 112, 2125-2130.

(94) Whitesides, R.; Frenklach, M. Detailed kinetic Monte Carlo simulations of graphene-edge growth. J. Phys. Chem. A 2010, 114 689-703.

(95) D'Anna, A. Combustion-formed nanoparticles. Proc. Comb. Inst. 2009, 32, 593-613.

(96) Akihama, K.; Takatori, Y.; Inagaki, K.; Sasaki, S.; Dean, A. M. Mechanism of the Smokeless Rich Diesel Combustion by Reducing Temperature. SAE Transactions 2001, 110, 648-662.

(97) Jaramillo, I. C.; Gaddam, C. K.; Vander Wal, R. L.; Huang, C.-H.; Levinthal, J. D.; Lighty, J. S. Soot oxidation kinetics under pressurized conditions. Combust. Flame 2014, 161, 2951-2965.

(98) Liu, Y.; Song, C.; Lv, G.; Cao, X.; Wang, L.; Qiao, Y.; Yang, $\mathrm{X}$. Surface functional groups and $\mathrm{sp} 3 / \mathrm{sp} 2$ hybridization ratios of incylinder soot from a diesel engine fueled with n-heptane and nheptane/toluene. Coal Structure 92 2016, 179, 108-113.

(99) Wang, L.; Song, C.; Song, J.; Lv, G.; Pang, H.; Zhang, W. Aliphatic $\mathrm{C}-\mathrm{H}$ and oxygenated surface functional groups of diesel incylinder soot: Characterizations and impact on soot oxidation behavior. Proc. Comb. Inst. 2013, 34, 3099-3106.

(100) Le, K. C.; Lefumeux, C.; Bengtsson, P.-E.; Pino, T. Direct observation of aliphatic structures in soot particles produced in lowpressure premixed ethylene flames via online Raman spectroscopy. Proc. Comb. Inst. 2019, 37, 869-876.

(101) Raj, A.; Man, P. L.W.; Totton, T. S.; Sander, M.; Shirley, R. A.; Kraft, M. New polycyclic aromatic hydrocarbon (PAH) surface processes to improve the model prediction of the composition of combustion-generated PAHs and soot. Carbon 2010, 48, 319-332.

(102) Frenklach, M.; Moriarty, N. W.; Brown, N. J. Hydrogen migration in polyaromatic growth. Proc. Comb. Inst. 1998, 27, 16551661 . 